\title{
OS DOIS CIRCUITOS DA ECONOMIA URBANA EM JOÃO CÂMARA/RN, BRASIL
}

\author{
two urban economy circuits of João Câmara IRN, Brazil
}

\author{
Aldo Dantas* \\ Matheus Augusto Avelino Tavares*
}

\begin{abstract}
Resumo
A partir do final dos anos 1980 a dinâmica territorial de João Câmara entra em uma nova fase, na qual os circuitos da economia urbana passam a ser, cada vez mais, predominante para a sua organização espacial, sobretudo porque temos o avanço intenso do consumo em todas as camadas da sociedade. Nesse sentido, o objetivo desse trabalho consiste em analisar a expansão dos dois circuitos da economia urbana na cidade de João Câmara, dando ênfase a sua atual configuração espacial, bem como para os fatores que influenciam essa expansão na cidade. Para tanto, realizamos levantamento de dados a partir de fontes e procedimentos. $\mathrm{Na}$ etapa que diz respeito às fontes, realizamos uma pesquisa bibliográfica e documental sobre temas relacionados à problemática em questão em bibliotecas, instituições públicas e privadas. Já no que diz respeito aos procedimentos, ou à produção de informações, realizamos entrevistas e aplicação de questionários com os principais agentes sociais envolvidos com os dois circuitos da economia urbana na cidade de João Câmara. Os resultados obtidos até o momento apontam que a economia urbana de João Câmara vem se expandindo, com maior intensidade, a partir do seu circuito inferior, mormente no que toca aos pequenos comércios e estabelecimentos de prestação de serviços que estão presentes em diversos subespaços da c:idade.
\end{abstract}

Palavras-chaves:Circuito inferior e superior da economia, João Câmara, Dinâmica territorial.

\begin{abstract}
From the end of 80 s the dynamic territorial in João Câmara goes to a new stage, which the urban economy circuit becomes, little by little, more ascendant to its spatial organization, mainly because we have the upgrade of consume in all levels of the society. In this way, the aim of this job consists in analyze the developed of the two urban economy circuit in João Câmara city, emphasizing its spatial configuration actually and also analyzing the factors influencing this expansion in the city. To get our proposal, we researched in sources and procedures. In this level concerning the sources we conducted a literature search and documentation on issues related in libraries and public and private institutions. Concerning the procedures, or the information's production, we performed interviews and questionnaires with the main social agents involved with the two urban economy circuits in João Câmara city. The results in the moment show us the urban economy in João Câmara expanding, with more intensity, in the lower circuit, usually in the small trades and the service establishments that are in diverse subspaces of the city.
\end{abstract}

Key words: Lower and upper circuit of economy, João Câmara, Territorial dynamic.

\begin{abstract}
Resumen
Desde finales de 1980 la dinámica territorial de João Câmara entra en una nueva fase en la que los circuitos de la economía urbana son, cada vez más predominante de la suya organización espacial, especialmente en medida que avance el consumo intenso de todas las capas de la sociedad. Por lo tanto, el objetivo de este estudio es analisar la expansión de los dos circuitos de la economía urbana en la ciudad de João Câmara, com énfasis en la suya actual configuración espacial, así como los factores que vengan a influenciar esa expansión de la ciudad. Así, hemos echo una recogida de datos a partir de fuentes y procedimientos. En el paso con respecto a las fuentes, hemos echo una busca bibliográfica y de documentación sobre algunos temas relacionados en cuestión en las bibliotecas y en las instituiciones públicas y privadas. En lo que se refiere a los procedimientos, o a la producción de informaciones, hemos realizado entrevistas y cuestionarios con los principales actores sociales envolucrados en los dos circuitos de la economía urbana en la ciudad de João Câmara. Los resultados obtenidos hasta ahora indican que la economía urbana de João Câmara se ha expandido, com una mayor intensidad, a partir de su circuito inferior, especialmente com respecto a las pequeñas empresas y establecimientos de servicios que se hacen presentes en los diferentes subespacios de la ciudad. Palabras clave:
\end{abstract}

Palabras claves: Circuito inferior y superior de la economía, João Câmara, Dinámica territorial.

(*) Prof. Dr. da Pós-Graduação em Geografia da Universidade Federal do Rio Grande do Norte - Av. Senador Salgado Filho, 3000 - BR 101 Km, 92 - Lagoa Nova, CEP 59.078-970, Natal (RN), Brasil - Tel: (+ 55 84) 9193-6288 - aldodantas@ufrnet.br

(**) Doutorando em Geografia Humana pela Universidade de São Paulo e Prof. Msc. do Instituto Federal de Educação, Ciência e Tecnologia do Rio Grande do Norte - Av. Senador Salgado Filho, 3000 - BR 101 Km, 92 - Lagoa Nova, CEP 59.078-970, Natal (RN), Brasil - Tel: (+ 55 84) 9193-6288 - aldodantas@ufrnet.br 


\section{INTRODUÇÃO}

No período histórico atual temos, cada vez mais, a incorporação de ciência, técnica e informação ao conteúdo dos territórios (SANTOS, 1994; 2005; 2006). No âmbito desse processo presenciamos uma reorganização da economia por meio de sua monetarização e do aumento do consumo para novos estratos da sociedade (SILVEIRA, 2007a), de modo podemos afirmar que uma dentre as várias maneiras de entendimento da dinâmica e funcionamento das cidades, passa pela compreensão de suas principais atividades econômicas, ou como diria Souza (2008), pelas suas atividades geoeconômicas. Em João Câmara, cidade localizada nas proximidades da Região Metropolitana de Natal/RN (Mapa 1), essas atividades dizem respeito, sobretudo ao comércio e à prestação de serviços, que exercem acentuada importância para a sua economia, principalmente nos últimos anos, quando a economia urbana torna-se determinante para o município como um todo, após a decadência das economias ditas tradicionais (FELIPE, 1986), especialmente aquelas relacionadas aos circuitos espaciais de produção do algodão e do sisal. Esta predominância da economia urbana revela-se por meio da renda gerada no município, a qual aproximadamente 90\% (IBGE, 2010a) é proveniente de atividades tipicamente citadinas, tais como o comércio, os serviços e os pequenos estabelecimentos industriais.

Nos últimos anos a economia urbana de João Câmara vem sofrendo intensa expansão de suas atividades, principalmente aquelas do circuito inferior da economia. O município tem hoje 527 estabelecimentos cadastrados junto a CDL (2010), mas de acordo com nosso levantamento de campo, este número pode atingir um total de aproximadamente 600, pois constatamos que esse cadastro não contemplou muitos dos ambulantes e dos vendedores itinerários existentes na cidade que não possuem um ponto fixo. Entendemos que mais de $90 \%$ do total de estabelecimentos da cidade, exercem atividades típicas do circuito inferior, uma vez que apresentam baixo nível de incorporação tecnológica, de organização e de capital. Desse modo, constata-se que a expansão das atividades econômicas em João Câmara está profundamente atrelada ao crescimento do circuito inferior da economia e com o aumento do consumo entre as camadas mais pobres da sociedade.

É importante destacar que embora João Câmara tenha uma tradição comercial relevante, constatamos que a cidade vem passando por um fenômeno relativamente recente de expansão do seu comércio e principalmente dos serviços, dado que do total de estabelecimentos registrados na CDL (2010) (tanto formais quanto informais), aproximadamente $50 \%$ foram inaugurados nos últimos 5 anos, e se estendemos o período para os últimos 15 anos, perceberemos que esse número chega próximo dos $70 \%$, o que, consequentemente, evidencia que se trata de um fenômeno relativamente novo e intenso. Não queremos dizer que a cidade só recentemente viu a expansão de seus estabelecimentos do circuito inferior, dado sua tradição, sobretudo para o comércio; o que se pode constatar é que a natureza é outra, pois novas formas de comércio e de serviços que não existiam outrora na cidade, tais como: estabelecimentos de vendagem de aparelhos de celulares e acessórios, de CDs e DVDs, financeiras, concessionárias de motocicletas etc., passaram a fazer parte da atual configuração do espaço geográfico de João Câmara.

Dito isso, podemos afirmar que essas atividades que vem se expandindo e configurando a economia e o território de João Câmara, fazem parte do que Santos $(1979,2008)$ denominou de Circuitos da Economia Urbana. Esse sistema teórico busca interpretar a economia das cidades a partir da existência de dois circuitos, um circuito superior - composto pelos bancos, comércio, indústria de exportação, indústria moderna, serviços modernos, atacadistas e transportadores; e um circuito inferior - que se constitui pelas formas de fabricação de uso não intensivo de capital, pelos pequenos comércios e pelos serviços não modernos, voltados, sobretudo, para o consumo dos mais pobres (SANTOS, 2008).

Os circuitos da economia urbana podem ser vistos, como subsistemas da economia urbana, no qual todas as formas de trabalho estão integradas (SANTOS, 2008). Eles têm a mesma origem, ainda que resultem direta e indiretamente de vários processos de modernização que atingem sele- 
tivamente e descontinuamente as porções do território. Nesse processo, é preciso destacar que o circuito inferior, em muitos casos, se torna dependente do circuito superior, sobretudo por causa dos serviços prestados por atacadistas, transportadores, fornecedores de crédito e, ainda, pelos produtos comercializados que em diversos aspectos procuram copiar aqueles do circuito superior; por isso, o circuito inferior não pode ser analisado de maneira isolada, pois ele mantém intensas relações com o superior, sejam essas relações de dependência ou não.

Nesse sentido, o objetivo desse trabalho consiste em analisar a expansão dos dois circuitos da economia urbana na cidade de João Câmara/RN, como ênfase na compreensão dos fatores que influenciaram na sua constituição, bem como na sua dinâmica e atual configuração espacial.

Faz-se mister destacar que não pretendemos somente realizar uma análise da economia urbana do município de João Câmara, mas intentamos contribuir na construção de uma metodologia para o estudo das cidades a partir da teoria dos circuitos da economia urbana desenvolvida por Santos (1979) e renovada por Silveira (2004, 2007a, 2007b), sobretudo, no que consiste ao estudo das cidades que não estão inseridas nas regiões metropolitanas e que se constituem na maioria dos municípios da formação socioespacial brasileira. Tais cidades vêm sendo estudadas e adjetivadas de médias e pequenas, o que, do nosso ponto de vista, se constitui num equívoco crasso, dado que entendemos que é preciso elaborar teorias para entendermos as cidades independentes de seu tamanho, pois o que é uma cidade média para São Paulo, com certeza não o é para o Rio Grande do Norte e vice versa.

Acreditamos que o sistema teórico totalizante dos dois circuitos da economia urbana oferece subsídios para o estudo das cidades independente de seu tamanho e/ou dimensões, pois busca compreender a totalidade das existências sociais, ou seja, busca o entendimento do uso do território através da relação dialética entre o circuito superior e o inferior, considerando que "a riqueza produzida pelo circuito superior não pode ser compreendida sem a pobreza própria do circuito inferior, que este também perpetua" (SILVEIRA, 2007a, p. 3).

$\mathrm{O}$ artigo está dividido em três partes. Na primeira fizemos uma análise das variáveis que contribuíram tanto para a constituição territorial de João Câmara quanto para a formação dos dois circuitos da economia urbana; na segunda, realizamos uma análise da existência e da dinâmica proporcionada pelos dois circuitos na cidade de João Câmara; e, por fim, apresentamos algumas conclusões.

\section{CONSTITUIÇÃO TERRITORIAL E VARIÁVEIS CHAVES PARA A EXPANSÃO DOS DOIS CIRCUITOS DA ECONOMIA EM JOÃO CÂMARA/RN}

Compreendemos que a constituição e atual configuração dos dois circuitos da economia urbana em João Câmara decorrem da conjunção de vários aspectos que ao longo dos anos foram delineando o seu território, indo desde variáveis relacionadas aos circuitos espaciais de produção do algodão e do sisal, marcantes em momentos pretéritos e em outra Divisão Territorial do Trabalho (DTT), chegando até os programas de assistência do Estado Brasileiro que, no curso dos últimos anos, favoreceram, sobremaneira, a expansão do consumo, sobretudo nas populações mais pobres.

Buscaremos, a partir da constituição territorial de João Câmara, levantar elementos que nos possibilitem compreender a atual dinâmica dos dois circuitos da economia na cidade. Nesse sentido, Milton Santos (1994), aponta que é preciso compreender o processo formativo das coisas, pois a análise do presente somente a partir dele próprio, pode dificultar o pleno entendimento dos processos e as formas de constituição dos territórios.

Partindo dessa análise pode-se dizer que a constituição territorial de João Câmara tem o seu início a partir de 1917 com a instalação de um grande objeto geográfico, a Estrada de Ferro Central do Rio Grande do Norte ligando Natal a Lajes, no interior do Estado. Uma das estações da ferrovia foi construída nas terras até então parcamente usadas, denominadas de Baixa Verde e posteriormente João Câmara (TORQUATO, 2009); (SILVA, 2006). Nesse período, podemos falar de um momento de "letargia" dessa região (SILVEIRA, 1999), dado que ainda predominava um meio natural, no 
qual a ação do homem ainda não produzia grandes objetos e nem era capaz de engendrar grandes fluxos que possibilitassem modificar a paisagem ou criar novas materialidades (SANTOS, 2006). No entanto, esse sistema de movimento pouco a pouco foi favorecendo a constituição de novos espaços que se destinavam tanto à produção como à comercialização de mercadorias (TORQUATO, 2009).

A densificação técnica desse meio geográfico se dá com a produção do algodão em larga escala, de modo que esse circuito espacial de produção foi fundamental para a constituição territorial de João Câmara, pois engendrou, direta ou indiretamente, um intenso movimento no território não só de produtos diversos e de populações, mas também de ordens e de capitais.

Em um primeiro momento, o circuito espacial do algodão em João Câmara compreendia o plantio, descaroçamento e seu escoamento, sendo que o espaço concentrador de funções era o da fazenda, pois duas das principais etapas do processo aí se localizavam. Cabia à pequena aglomeração urbana então existente realizar as funções da comercialização do produto e seu escoamento por meio do novo sistema de movimento recém constituído.

A partir de meados dos anos 20 e início da década de 1930 dois eventos se mostram fundamentais no processo de formação territorial de João Câmara, são eles: as transformações na divisão territorial do trabalho e as mudanças na constituição do circuito do algodão. O primeiro está diretamente relacionado ao processo de industrialização da região Sudeste que promove uma mudança no processo de circulação dessa mercadoria, uma vez que se outrora o principal centro consumidor era a Inglaterra, a partir desse momento passou ser São Paulo e Rio de Janeiro que expandiam de maneira intensa sua indústria têxtil, demandando uma quantidade maior dessa matéria prima (TAKEIA, 1981). Este processo teve grande repercussão no território potiguar e, particularmente, para as áreas produtoras de algodão; no caso de João Câmara, tivemos uma expansão da área produzida que se materializou no espaço geográfico por meio da existência de três usinas de beneficiamento e uma de produção de óleo, ligadas às firmas de João Câmara \& Irmãos e de Fernando Gomes Pedrosa.

O segundo evento supracitado, proporcionou uma mudança na constituição do circuito espacial do algodão. Trata-se da saída das máquinas do interior das fazendas e sua localização em pequenos aglomerados que se tornaram cidades-sedes de vários municípios (CLEMENTINO, 1987); (FELIPE, 2010). Tal processo mudou radicalmente a organização e dinâmica territorial de João Câmara, sobretudo porque as usinas de beneficiamento que aí se constituíram intensificaram sua expansão territorial e seu processo de urbanização (SILVA, 2006). Assim, a partir dessa conjuntura, toda a produção do algodão se dirigia para a cidade para então ser comercializada, beneficiada e escoada para Natal por meio da rede ferroviária, para então ser exportada.

Além disso, nesse momento temos uma densificação técnica do circuito espacial do algodão que promoveu a emergência de uma usina produtora de óleo a partir do seu caroço. É assim que nasce mais uma "solidariedade técnica" para usarmos as palavras de Milton Santos (2006), pois o início do beneficiamento do caroço do algodão e sua transformação em óleo permitiram o surgimento da usina, o que possibilitou o aumento da demanda por essa matéria prima e, por conseguinte, a expansão da área produzida.

Essa valorização do circuito espacial do algodão coloca em evidencia uma hierarquização e um controle dos lugares tanto em nível do território nacional, quanto em nível do sistema internacional ou da economia-mundo. Desse modo, na dimensão nacional, a hierarquização se dá tanto por meio do controle da produção que era exercido pelos grandes fazendeiros que impunham o seu sistema de produção aos trabalhadores rurais, quanto ao nível da circulação e comercialização que, em parte, é controlado pelos grandes empresários ligados à indústria têxtil do Rio de Janeiro e de São Paulo, principais compradores do produto.

A hierarquização dos lugares e controle do circuito espacial do algodão se concretiza com a participação das grandes corporações internacionais das quais as três irmãs, SAMBRA, CLAYTON e MACHINE COTTON, que atuaram amplamente no território potiguar, são os melhores exemplos. Conforme expõem Oliveira (1981, p. 48) são esses "grandes trustes internacionais que controlam 
a circulação internacional" e os preços dessa matéria prima a fim de mantê-los a níveis mínimos que garantam a extração de uma mais-valia que já se mostrava mundializada.

A intensificação e manutenção do circuito do algodão, por cerca de três décadas, foi fundamental para a constituição de um comércio tipicamente do circuito inferior. De acordo com Torquato (2009, p. 35) a partir de 1921-1923 a feira semanal começa a se desenvolver na cidade, tanto a partir de produtores que se direcionavam para esse espaço com o objetivo de comercializarem suas mercadorias, quanto por meio daqueles que para aí convergiam para adquirir novos bens. Pode-se dizer que temos aí o início de uma das feiras livres mais importantes do estado e a mais importante da região em termos de dinâmica geoeconômica.

Essa dinâmica do circuito espacial do algodão que perdurou até mais ou menos os anos 1950 e 1960, deixou profundas marcas na organização e dinâmica territorial de João Câmara que se tornou a principal cidade de sua região, tanto do ponto de vista do circuito do algodão quanto do comércio que era alimentado pelo grande fluxo de capital e de mercadorias que o circuito proporcionou, sobretudo em tempos de safras.

Após esse período, ao mesmo tempo em que presenciasse certo processo de retraimento do circuito do algodão, João Câmara vê o surgimento do circuito espacial do sisal. A expansão deste circuito nos revela traços de um novo processo de mundialização que então se configurava, uma vez que atendia a mercados internacionais que, sobretudo a partir da Segunda Guerra Mundial, passaram a demandar mais dessa matéria prima.

Assim, à medida que o mercado mundial e nacional aumentava sua demanda, o circuito espacial do sisal pouco a pouco incorporou terras ao seu processo produtivo e avançou em áreas que outrora eram destinadas ao circuito do algodão. Esta realidade traz à tona um processo de refuncionalização do território e o advento de uma nova divisão territorial do trabalho, que neste caso esteve pautada na exportação do sisal. É bem verdade que a lógica hierarquizada de organização dos territórios permanece, pois os centros de comando desse circuito estão estabelecidos nas mesmas áreas que o seu antecessor, ou seja, na região Sudeste, no território nacional, e na Europa a nível mundial.

Se no circuito do algodão o processo de produção era fragmentado em vários pequenos e médios produtores, mesmo com a existência de duas grandes empresas no município, no caso do sisal percebe-se uma grande concentração do processo produtivo. Em João Câmara foi a Companhia Industrial de Fibras S/A (SISAF), a empresa que comandou todas as etapas do processo, pois além de deter uma grande fazenda que era responsável pela maior parte de sua produção, a empresa era responsável pelo beneficiamento, comercialização e pelo escoamento do produto até o seu destino final no território potiguar, que era o Porto de Natal.

Esse processo tecnifica ainda mais o meio geográfico de João Câmara, tanto do ponto de vista do uso de transportes para o escoamento da produção, quanto por meio do uso de maquinários como, por exemplo, de tratores, para fazer a preparação das terras para plantio, bem como para seu cultivo.

De acordo com Oashi (1999), mesmo com a produção de fibras sintéticas a partir de meados dos anos 1960, verifica-se, sobretudo nos anos 1970, uma grande expansão do espaço produtivo do sisal, uma vez que várias indústrias de manufaturados de sisal passaram a incorporar novas técnicas que tornavam o produto mais competitivo no mercado nacional e internacional. É justamente nesse período que a SISAF amplia sua área de produção em João Câmara e transforma o circuito do sisal no principal dinamizador da organização territorial do município.

Destacamos que a expansão do circuito do sisal não se deu somente em João Câmara, mas em vários municípios do território potiguar, onde imensas áreas de produção passaram a configurar espaços de monocultura, dada a vastidão das áreas ocupadas. Dos anos 1970 até meados da década de 1980, a exportação do sisal, segundo Santos (1999), atingiu o seu apogeu com a quantidade de 21.000 toneladas somado todo território potiguar em uma única safra, sendo que João Câmara tornou-se um dos principais produtores devido à hegemonia da SISAF. 
A dinâmica proporcionada por esses circuitos de produção (algodão e sisal) se refletiu na constituição territorial por meio do processo de urbanização e pela formação de um comércio que apresentou grandes fluxos, não somente nos dias da feira semanal, uma vez que para aí convergiam pequenos e médios produtores de toda a Baixa Verde, mas também pela existência de um comércio permanente que era ainda mais fortalecido nos períodos de safras desses produtos, haja vista que o fluxo de capital aumentava substancialmente. Podemos afirmar que parte da dinâmica dos dois circuitos da economia urbana de João Câmara atualmente, é tributária das materialidades (feira e comércio) e temporalidades (urbanização) fomentadas pelos circuitos espaciais do algodão e do sisal.

Dadas as características citadinas desses circuitos espaciais de produção, eles engendraram um processo de urbanização em João Câmara que se mostrou ascendente desde a década de 1970, e se intensificou nos anos 1980, repercutindo até o início da década de 1990, quando se verifica uma falência desses circuitos proporcionada por uma série de fatores, tais como: entrada no mercado de produtos sintéticos, pragas naturais e pela não modernização do processo produtivo (CLEMENTINO, 1987; FELIPE, 1986).

Com isso, outra variável que emerge como fundamental para o pleno entendimento da constituição dos dois circuitos da economia urbana em João Câmara é a análise do processo de urbanização. De acordo com dados do IBGE (BRASIL, 1970; 1980; 1991; 2000; 2010b), nos últimos quarenta anos João Câmara presenciou não somente o aumento de sua população que passou de 18.297 em 1970 para 22.826 em 1980, 25.854 em 1991, 29.248 em 2000 e para 31.518 em 2010, mas uma expansão do seu processo de urbanização, uma vez que sua população urbana passou de 8.307 em 1970 para 12.759 em 1980, 17.694 em 1991, 19.956 em 2000, e para mais de 22.000 habitantes em 2010 (Figura 1), o que evidencia um acréscimo substancial na população urbana, que nesse período quase triplica. Esta realidade quando somada ao crescimento total da população acaba funcionando como incremento para o alargamento do mercado consumidor da cidade.

Não obstante, compreendemos que esse processo de urbanização não somente faz crescer a população residente na cidade, mas também introduz novos hábitos e costumes, realidade que também contribui para emergência de novas formas de comércio, de serviços e de produção. Então, a expansão dessas atividades em João Câmara também possui relação direta com o avanço do dito "consumo moderno" em todas as camadas sociais, mesmo "se essa participação é parcial ou ocasional nas camadas menos favorecidas", conforme argumenta Santos (2008, p. 37).

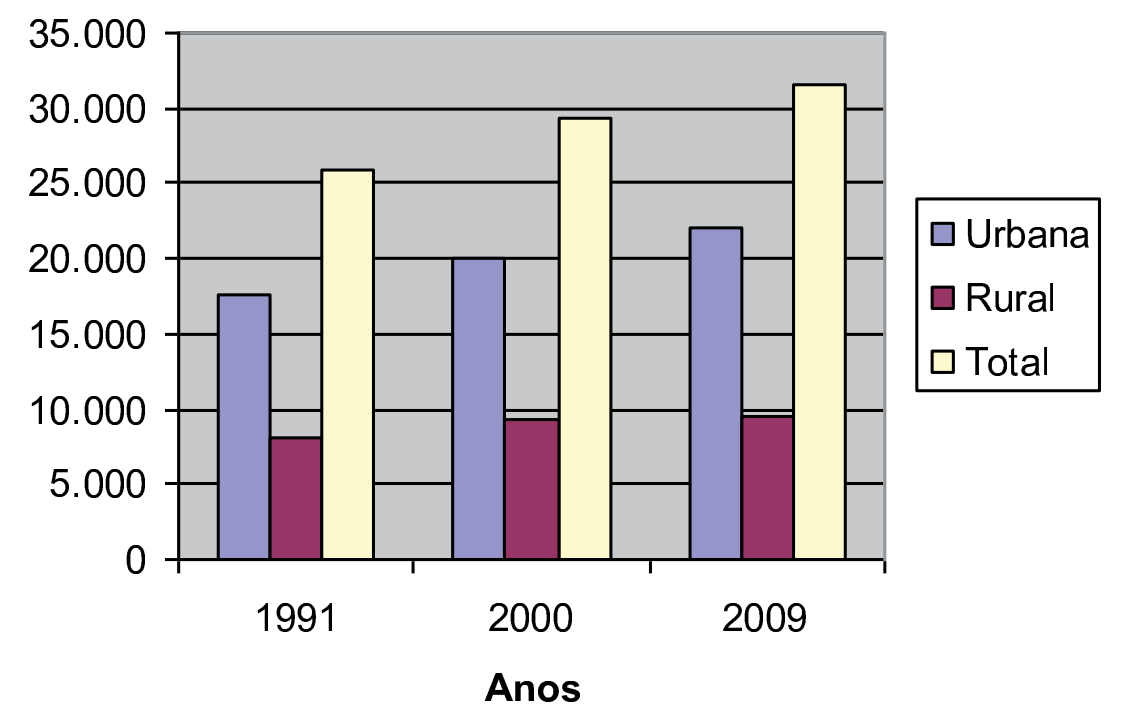

Figura 1 - Gráfico da Evolução populacional em João Câmara Fonte: Elaboração própria a partir de dados do IBGE

Na mesma proporção em que cresce a população da cidade e que se introduzem novas formas de consumo, verifica-se um incremento no número de estabelecimentos, especialmente aqueles do 
circuito inferior, mais notadamente os de comércio e de serviços, que correspondem a aproximadamente 95\% (CDL, 2010) das atividades existentes na cidade.

Podemos dizer que essa expansão do consumo também tem relação direta com a disseminação do meio técnico-científico-informacional (SANTOS, 2005) para distintas partes do território, dado que o mesmo traz em seu bojo a banalização e disseminação de inúmeros objetos técnicos que, devido à expansão do crédito e ao aumento do poder de consumo da sociedade, tornaram-se de fácil acesso, até mesmo para os segmentos mais pobres da sociedade. Por isso, o autor afirma que no Brasil "a gama de artigos de consumo aumenta enormemente. A expansão do consumo da saúde, da educação, do lazer, é paralela à do consumo das batedeiras elétricas, televisões, e de tantos outros objetos" (SANTOS, 2005, p. 52)

Outro fator para entendermos o processo é aquele da publicidade que vem impulsionando o consumo moderno, publicidade esta que invade o cotidiano da sociedade através da difusão de informações veiculadas pelas mais variadas formas de comunicação, tais como: rádio, televisão, telefones e internet (CONTEL, 2006).

Em João Câmara a publicidade acontece por meio da utilização de banners, cartazes, cartões, folhetos, rádios locais e através de carros e motos de som que diariamente percorrem as principais vias da cidade para divulgarem os produtos dos principais estabelecimentos. Vale destacar que a produção dessas formas de publicidade é realizada pelos próprios agentes desse circuito, através do uso de computadores e em associação com pequenos estabelecimentos gráficos. De acordo com dados da CDL (2010), aproximadamente $40 \%$ dos estabelecimentos fazem algum tipo de publicidade como forma de divulgarem os seus empreendimentos.

Se nas grandes metrópoles a materialização dessas novas formas de consumo impulsionadas pela publicidade se dá também através dos hipermercados e dos shoppings centers, numa cidade interiorana como é João Câmara, a geograficização das novas formas consumo ocorre por meio de uma acentuada expansão do circuito inferior, principalmente por meio dos estabelecimentos que comercializam produtos que, na realidade, são imitações de grandes marcas nacionais e internacionais, ou ainda por meio das inúmeras lojas locais de produtos técnicos contemporâneos, tais como as de telefones celulares e as de eletrodomésticos.

Ainda merece ressalva que em se tratando de circuito inferior da economia, a sua expansão também tem relação direta com a questão do desemprego, que no período histórico atual atinge um maior número de pessoas e, no caso de uma região pobre como é a de Baixa Verde, essa realidade se faz sentir com maior intensidade. É difícil estabelecer com exatidão o número de pessoas desempregadas, mas os dados existentes para estado do Rio Grande do Norte indicam que aproximadamente $11 \%$ da população está desempregada (DIEESE, 2007); e para João Câmara este número pode variar, de acordo com dados do Ministério do Trabalho e Emprego (BRASIL, 2010c); entre 10\% e 12\%.

O fato é que com taxas de desemprego como estas é, consequentemente, cada vez maior o número de pessoas que buscam abrigo no circuito inferior; nas palavras de Silveira (2004, p. 10) essas pessoas devem "encontrar una actividade - y un lugar dentro de la ciudade - que sea capaz de permitir su supervivencia". Tal realidade tanto vale para aquelas pessoas que perderam os seus empregos e que nunca mais conseguiram recuperá-lo, quanto para aquelas inúmeras pessoas que nunca tiveram a oportunidade de conseguir outra forma de emprego; em ambos os casos, o circuito inferior aparece como alternativa devido à sua flexibilidade que permite que, com um pequeno volume de capital, se abra um "negócio" qualquer, e às vezes não é sequer necessário ter este capital, como ocorre, por exemplo, com os vendedores ambulantes das mais variadas naturezas que trabalham no regime de concessão de mercadorias, no qual eles recebem uma quantidade determinada e ao final de um período estabelecido eles prestam conta do que foi vendido.

Santos (2008, p. 202), diz que o circuito inferior é "uma estrutura de abrigo para os citadinos, antigos ou novos, desprovidos de capital e de qualificação profissional". Os números existentes acerca dos principais problemas das atividades econômicas de João Câmara, somente vêm ratificar 
essa afirmação, na medida em que, segundo dados da CDL (2010), 40,91\% dos estabelecimentos de comércio, $44,51 \%$ dos de serviços e $66,67 \%$ das indústrias apontam como principal problema de seus negócios a escassez de capital de giro, o que tem repercussão direta nas dificuldades de adquirir matéria prima, máquinas e equipamentos que permitam uma organização e uma modernização de seus empreendimentos.

Outro ponto que também corrobora com a afirmação supracitada é o nível de escolaridade dos trabalhadores que exercem atividades típicas do circuito inferior, sendo que essa realidade é ainda mais agravante quando nos referimos aos estabelecimentos ditos "informais", dado que, de acordo com nosso levantamento, somente $42,94 \%$ dos trabalhadores possuem o ensino médio completo no setor formal, e por sua vez, no setor informal, esse número é de apenas $28,84 \%$.

Outra variável importante para entendermos a expansão dos circuitos na cidade de João Câmara, é o aumento do poder de consumo da sociedade, sendo que esta questão se revela por meio de quatro aspectos fundamentais: acesso ao crédito (tanto público quanto privado), aumento dos programas de transferência de renda, pelo substancial número de aposentadorias e pelos funcionários públicos. Para as cidades do interior e particularmente na cidade em questão, tais aspectos funcionam como a principal mola propulsora para dinâmica dos circuitos.

Quanto ao primeiro aspecto podemos dizer que a disseminação do crédito é uma característica do período atual e está relacionada ao fato de que as grandes redes financeiras e as agências bancárias (públicas e privadas), típicas do circuito superior, tendem a não deixar de lado nenhuma parcela do território nacional e da economia, o que, por consequência, vem ampliando a capilaridade das agências e a oferta de diversas formas de crédito aos usuários. Em João Câmara, de acordo com pesquisa de campo, essa oferta de crédito tem incrementado o consumo para todas as camadas sociais e é realizada tanto por meio das agências estatais, como Banco do Brasil e Caixa Econômica Federal, quanto por intermédio de pequenas filiais de várias instituições financeiras, como, por exemplo, as agências do Panamericano, BMC, Cruzeiro do Sul, Santander, Mercantil do Brasil, BGM, Losango dentre outras existentes na cidade. No total são aproximadamente 10 agências de financiamento que exercem uma política audaciosa de busca por clientes. De acordo com Lima (2009, p. 18), essas redes financeiras "chegam a fazer hoje atendimento nas casas. Elas conseguem os telefones de clientes em potencial (provavelmente junto ao INSS, ao Estado e às prefeituras) e agendam visitas às casas", para lhes oferecer as suas linhas de crédito.

É sempre relevante destacar que tais instituições, embora apresentem taxas de "juros leoninas" (SILVEIRA, 2007a) têm, em muitos casos, uma ampla atuação no seio da sociedade, sobretudo para aqueles agentes sociais que trabalham como pessoa física e que, por isso, possuem dificuldades para conseguir acesso ao crédito dos bancos; para esses agentes, essas financeiras acabam sendo a saída mais fácil, tendo em vista que disponibilizam créditos mais fáceis e rápidos do que os bancos que possuem uma burocracia maior para a realização de empréstimos.

Todavia, é preciso destacar que, se em um primeiro momento essa expansão das redes financeiras funciona como combustível para a intensificação do consumo, pois de posse do crédito as pessoas movimentam um volume maior de dinheiro para a aquisição de produtos; em um segundo momento, esse processo acaba se tornando um entrave para a continuação do consumo, uma vez que as pessoas assumem uma dívida que, em alguns casos, pode comprometer até $30 \%$ do orçamento, o que, consequentemente, inviabiliza a continuação do consumo por um longo período (12-60 meses), ou seja, depois da euforia segue um período de endividamento e pagamento de altas taxas de juros.

A expansão dos sistemas de crédito bem como a existência do circuito superior em João Câmara também se dá por meio da disseminação dos cartões de crédito, que são aceitos nos mais variados estabelecimentos da cidade, desde pequenas lojas a redes de supermercados, sendo que as bandeiras mais utilizadas são master-card, visanet e hiper-card que, sendo as bandeiras com maior capilaridade, são as mais difundidas entre as classes populares da cidade de João Câmara. Entre 20 e 30\% (CDL, 2010) dos estabelecimentos já utilizam esses sistemas de créditos e acreditamos 
que esse número tende a aumentar, pois muitos comerciantes afirmam que esta é uma tendência que deve ser seguida por muitos outros que procuram ampliar suas vendas.

Nos últimos seis anos, o alargamento dos programas de transferência de renda do governo federal também tem incrementado sobremaneira o poder de consumo da sociedade, sendo que isso se torna mais intenso nas cidades que não apresentam a mesma dinâmica econômica que as regiões metropolitanas, uma vez que esta fonte de renda acaba sendo uma das principais mantenedoras do consumo, principalmente, aquele que impulsiona o circuito inferior. Em João Câmara, esses programas têm impulsionado o comércio local, dada a quantia de recursos que entram mensalmente no município que, embora seja baixa por família, quando somamos o montante final temos um volume considerável, que é capaz de manter níveis mínimos de consumo para as camadas mais pobres. De acordo com dados do Ministério do Desenvolvimento Social e Combate a Fome (MDS) (BRASIL, 2010d), na cidade de João Câmara são 4.461 famílias recebendo os auxílios do Bolsa Família, o que quando somado atinge $\mathrm{R} \$ 465.000,00$, ou seja, um volume de dinheiro que possibilita um incremento a mais para o consumo na cidade, favorecendo a expansão de diversas formas de consumo.

Somem-se a isso o montante gerado pelas aposentadorias e pelos funcionários da administração pública que, no estado do RN como um todo, constitui-se na principal fonte de renda para as famílias. É a partir dessa renda que tanto temos o financiamento das motocicletas e de eletrodomésticos, quanto a aquisição dos produtos mais básicos para a sobrevivência humana. De acordo com um comerciante, proprietário de um pequeno estabelecimento no centro da cidade, são as aposentadorias e os funcionários públicos, bem como os benefícios do Bolsa Família que, grosso modo, movimentam o comércio de João Câmara, tanto os pequenos estabelecimentos quanto aqueles maiores, de modo que se tirarmos a renda gerada por essas duas categorias, o comércio da cidade não resiste.

Também exerce significativa importância para a intensificação dos circuitos em João Câmara a situação geográfica de primazia que a cidade se encontra dentro da rede urbana da região de Baixa Verde, ou seja, as relações que a cidade desenvolve com o seu entorno emergem como ponto fundamental para entendermos a dinâmica de sua economia urbana. Santos (1980, p. 157), enfatiza a necessidade de compreendermos uma cidade em relação com a rede urbana na qual se insere ao dizer que "as pesquisas feitas na perspectiva do acondicionamento do território mostram que, quando se quer conhecer a realidade viva de uma economia urbana, é preciso considerar o conjunto das células urbanas de uma dada região".

Essa influência sobre as demais cidades da rede se dá, sobretudo no que concerne às atividades de comércio e de serviços, uma vez que parte da população dessas cidades vizinhas encontra em João Câmara o lócus para a realização do consumo. De acordo com os comerciantes, entre 25\% e 30\% do público que consome no comércio local são de pessoas oriundas de cidades vizinhas, sendo que as cidades que apresentam uma maior conexão espacial com João Câmara são as que compõem a Região de Baixa Verde, a saber: Poço Branco, Parazinho, Bento Fernandes e Jandaira. Também constatamos que populações de outras cidades também se deslocam para João Câmara para satisfazerem suas necessidades (mapa 2), o que somente vem a confirmar a dinâmica dos circuitos existente nessa cidade, bem como o papel de João Câmara na rede urbana regional, ou ainda pode nos revelar que a influência dessa cidade não se resume somente aos municípios da região da qual ela é a cidade principal, mas atinge outras cidades.

Embora a procura ocorra pelos mais variados tipos de estabelecimentos, constatamos que essas populações buscam com maior intensidade aqueles do setor moveleiro, de eletrodomésticos, de roupas e de aparelhos de telefonia móvel. De modo geral, a procura ocorre com maior ênfase no período que compreende o final e o início de cada mês; além disso, a feira livre de João Câmara é também bastante movimentada, principalmente, por aquelas populações que vivem nas áreas rurais desses municípios e que se deslocam para esse espaço em busca de alimentos e roupas. De acordo com um comerciante, possuidor de um pequeno mercadinho, os dias de feira são os mais intensos do comércio, sobretudo porque nesses dias a circulação de pessoas pelas ruas da cidade é mais de duas vezes maior que às dos dias normais. 
Desse modo, o grande fluxo de pessoas que circulam diariamente na cidade, mas, principalmente, no dia da feira semanal, está diretamente relacionada à influência que esta cidade exerce sobre aquelas que estão ao seu entorno, dado a sua maior dinâmica para o comércio e serviços.

Não obstante, é preciso atentar que os circuitos se retroalimentam, de modo que a massa de salários gerada em um circuito acaba fomentando o consumo no âmbito do sistema como um todo. No caso de João Câmara, como temos uma enorme predominância do circuito inferior, é este com o seu montante de renda gerado, que mais alimenta, tanto o seu próprio crescimento, quanto o do circuito superior. Quanto ao consumo neste circuito, podemos exemplificar com o caso do pequeno comerciante ou do proprietário da cigarreira que compra a motocicleta em uma das concessionárias da cidade. Nesse sentido, trata-se de uma interação entre os circuitos, situação que somente comprova uma assertiva de Santos (2008, p. 261), segundo a qual "os dois circuitos não são dois sistemas isolados e impermeáveis entre si, mas, ao contrário, estão em interação permanente".

Em síntese, essas variáveis, quando tomadas em conjunto, nos permitem compreender como e porque os circuitos da economia, mas principalmente, o circuito inferior vem se expandindo na cidade de João Câmara; além do mais revelam que dependendo do contexto analisado, novas variáveis podem vir à tona para explicação dos circuitos.

\section{OS CIRCUITOS DA ECONOMIA E SUA CONFIGURAÇÃO ESPACIAL NO MUNICÍPIO DE JOÃO CÂMARA}

Com base no que já foi exposto, podemos dizer que ao mesmo tempo em que presenciamos a intensificação do processo de urbanização da sociedade (SANTOS, 2005), temos uma expansão acentuada do circuito inferior da economia, sobretudo porque o atual processo de urbanização é, cada vez mais, guiado pelas lógicas de reprodução desigual e combinada do capital (SMITH, 1996), que faz com que as atividades mais modernas, típicas do circuito superior, se concentrem nas regiões metropolitanas e nas cidades mais dinâmicas do território nacional, ficando as demais cidades, na maioria das vezes, excluídas desse processo. Todavia, isso não quer dizer que essas cidades não tenham atividades do circuito superior, o fato é que estas se apresentam, via de regra, de maneira pontual, de modo que na economia urbana dessas cidades prevalecem as formas de trabalho típicas do circuito inferior.

Em João Câmara, como na maioria das cidades do território potiguar, esta realidade se faz candente, pois é cada vez mais intensa a presença do circuito inferior, com destaque para os pequenos comércios e estabelecimentos de prestação de serviços, que estão presentes em diversos subespaços da cidade. Do total de estabelecimentos existentes, conforme já pontuado, calculamos que cerca de 95\% faz parte do que se chama de circuito inferior da economia urbana, dado que apresentam os seus principais elementos constitutivos, tais como: organização precária, baixo índice de capitalização e de incorporação tecnológica. Esses números, além de demonstrarem a importância desse circuito na dinâmica territorial de João Câmara, também nos revelam o peso desse circuito na absorção de mão de obra na cidade, mesmo que parte considerável desses empregos sejam precários

Nesse sentido, constatou-se que do total de empregos existentes na cidade, mais $50 \%$ não garantem os direitos fundamentais do trabalhador, e, em alguns casos, nem mesmo o salário mínimo é garantido. A análise com base nos dados do MTE (2010), que tem como enfoque central a questão da Formalidade e Informalidade das atividades, também aponta nesse sentido, dado que apresenta que aproximadamente $60 \%$ dos postos de trabalho existentes na cidade estão em condições de informalidade. Mesmo sabendo que este enfoque está permeado por diversas inconsistências tanto do ponto de vista teórico quanto empírico, conforme demonstraram Santos (1979), Silveira (2004) e Montenegro (2009), sobretudo, por que não considera as relações de complementaridade contraditórias existentes entre as atividades econômicas (formais e informais); ele nos revela a situação de precariedade das formas de trabalho existentes em João Câmara. 
Tais formas precárias de trabalho encontradas na cidade em questão, somente vêm comprovar a relação contraditória que permeia a formação e dinâmica dos dois circuitos da economia, e, em particular, do circuito inferior, uma vez que ao mesmo tempo em que ele pode funcionar como uma estrutura de abrigo para os segmentos mais pobres da cidade, o mesmo também reproduz a situação de pobreza dessas pessoas, porque além delas serem desassistidas dos direitos mais básicos do trabalhador, os seus ganhos somente permitem a reprodução mínima de sua existência.

$\mathrm{O}$ aumento no número empregos também nos revela a dinâmica dos circuitos da economia na cidade de João Câmara, principalmente o circuito inferior, pois a maior parte desses empregos está diretamente relacionada a esse circuito. De acordo com dados do MTE (2010), podemos constatar que a partir de 2002 o número de empregos passa a ter sucessivos anos elevação em suas taxas. Mesmo registrando-se um recuo nos anos 2004 e 2006, o acréscimo no número de empregos vai se verificar até o presente ano. O período de maior intensidade desse aumento do emprego urbano se dá no triênio que compreende os anos 2007/2008/2009 (Figura 2). Vale destacar que é justamente nesse momento que a renda da sociedade brasileira passou por uma elevação, o que, por consequência, pode ter funcionado como estímulo para o aumento de consumo.

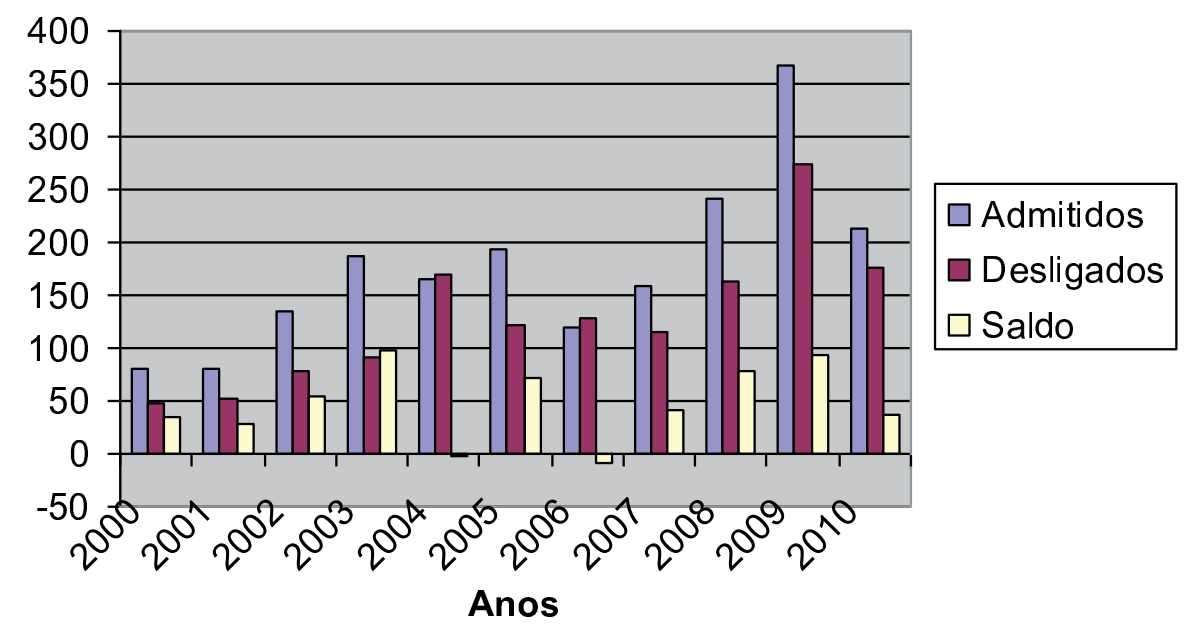

Figura 2 - Gráfico da Evolução do emprego em João Câmara Fonte: Elaboração própria a partir de dados do Ministério do Trabalho

A dinâmica desses circuitos para a economia de João Câmara também é revelada a partir de uma análise da renda gerada no município em sua totalidade. Com base nos dados existentes, constatamos que os dois circuitos respondem por aproximadamente 90\% (IBGE, 2010) da renda gerada em João Câmara, sendo que o comércio é o que apresenta uma maior dinâmica. Realizando um cruzamento entre os dados MTE (2010) e do IBGE (2010), conclui-se que do total de empregos existentes na cidade, cerca de $45 \%$ provêm do comércio, tal número somente revela o quanto essa atividade é importante na absorção de mão de obra.

Essa maior expressividade do comércio dá-se tanto porque João Câmara sempre teve uma tradição para essa atividade econômica desde os tempos do algodão e do agave, quanto porque, conforme afirma Salgueiro (1989, p. 158), “em termos económicos a actividade comercial é a mais relevante na circulação económica do capital, pois é através da venda que o capital-mercadoria se torna a converter no capital-dinheiro, indispensável à prossecução de novo ciclo produtivo".

Como o circuito inferior é o que apresenta maior expansão na cidade, pudemos constatar que essa expansão está se realizando por meio de uma pulverização das atividades econômicas e com uma consequente expansão dos micronegócios ou dos micros estabelecimentos. Aliás, Santos (2009) já havia destacado que a pulverização das atividades econômicas é uma característica essencial do circuito inferior. Assim, João Câmara conta com inúmeros pequenos estabelecimentos, 
os quais, em muitos casos, só abrigam um funcionário que pode ser o próprio proprietário ou um parente seu (filho ou cônjuge). Nesses estabelecimentos, o predomínio do trabalho familiar, da baixa incorporação de capital, tecnologia e de informação é uma realidade concreta, de modo que temos aí o desenvolvimento de uma atividade econômica, na qual o que é intenso é o trabalho dos funcionários, o que não deixa de ser uma contra-racionalidade (SILVEIRA, 2004), tendo em vista as características do período atual.

Mesmo que a cidade tenha espraiado o seu tecido urbano o que, por consequência, fez surgir inúmeros pequenos estabelecimentos em suas áreas mais periféricas, principalmente os comércios de gêneros alimentícios (as bodegas ou mercearias), a área central, as suas adjacências e as ruas que estão imediatamente conectadas a esse núcleo urbano, são os espaços que se apresentam como o lócus mais dinâmico da economia de João Câmara. De modo geral, podemos dizer que é nessa porção da cidade que o circuito inferior evidencia toda a sua diversidade, dado apresentar concentração significativa de estabelecimentos.

$\mathrm{Na}$ área central de João Câmara é possível encontrar diversas formas de trabalho que tanto adaptam o meio construído às suas necessidades, como é o caso de inúmeras residências que se tornaram pequenos comércios, quanto as que se adaptam a esse meio construído, principalmente no que concerne a busca por localidades próximas às vias mais dinâmicas dessa área.

Autores como Santos (2008) e Correa (2006) já demonstraram, de diferentes formas, a importância da área central para a configuração espacial e dinâmica das cidades. Usando Santos (2000), como referência, podemos dizer que o centro é o espaço par excellence das rugosidades, dado apresentar diversas divisões territoriais do trabalho sobrepostas. Nesse sentido, é necessário apreendermos que a área central de João Câmara é a parte mais acessível da cidade e é onde as atividades econômicas começaram a se desenvolver a partir da relação direta entre os fluxos de pessoas, capitais e mercadorias com as determinações do meio construído. Devido a sua maior carga de temporalidades materializadas no espaço, o centro de João Câmara acaba influenciando a localização das mais variadas formas de estabelecimentos.

Desse modo, esta área central é dominada pelo comércio e serviços que se imbricam e formam um espaço de atração, que influencia tanto a população que deseje estabelecer alguma relação econômica, quanto novos empreendedores que intentam iniciar um novo negócio. De modo geral, esta área compreende as ruas Cícero Varela, Pe. João Maria, Sete de Setembro, Vereador Severiano da Câmara, Monsenhor Walfredo Gurgel bem como toda a área que circunda a Praça Baixa Verde e a Praça Antônio Justino Souza. É nesse subespaço que se concentram enorme quantidade de estabelecimentos das mais variadas naturezas, tais como: lojas de eletrodomésticos, de moveis, de roupas, estabelecimentos de administração pública, redes de supermercados, pequenos mercadinhos, perfumarias, farmácias, concessionária de motocicletas, bancos, agências de crédito, estabelecimentos de alimentação, lojas de material de construção, de DVDs, CDs e de importados em geral. Podemos afirmar que aí os dois circuitos da economia aparecem de maneira imbricada e convivendo lado a lado e, em alguns casos, disputando a mesma clientela.

Dentre as atividades estabelecidas na área central de João Câmara, destacamos inicialmente aquelas pertencentes ao circuito inferior, mas que apresentam uma relação direta com o circuito superior, tais como: lojas de roupas e de calçados e os pequenos comércios CDs/DVDs. Quanto as primeiras (lojas de roupas e de calçados) é importante destacar as colocações de Santos (1979) e Silveira $(2004,2007 \mathrm{a})$, quando estes argumentam que um dos pilares do funcionamento do circuito inferior é a imitação de produtos típicos do circuito superior. Desse modo, grande parte dos produtos comercializados nesses estabelecimentos é, na realidade, uma reprodução daqueles produzidos pelas grandes marcas internacionais (Nike, Puma, Adidas, Yves Saint Laurent, Colcci, etc.), que apresentam considerável influência no consumo da sociedade. Assim, se reproduzem na escala do lugar, formas de consumo engendradas pela economia globalizada.

Além disso, a partir de nossas análises, pudemos constatar que, em muitos desses estabelecimentos, coexistem vários circuitos espaciais de produção. Tanto temos comerciantes que estão 
inseridos no circuito de produção de roupas de Caruaru, Fortaleza e de São Paulo, se bem que este aparece com menor frequência; quanto aqueles que se inserem nos circuitos dos calçados das cidades serranas do Rio Grande do Sul e do Ceará. De maneira geral, esses comerciantes fazem compras no atacado nos comércios especializados existentes nessas cidades ou em outras capitais, para em seguida revenderem em João Câmara.

Já os pequenos estabelecimentos de CDs e DVDs são uma constante no espaço urbano de João Câmara, sobretudo, porque no período atual eles não são procurados somente pelos grupos sociais que não tem condições de adquirir produtos originais, mas também por pessoas que apresentam amplas condições de consumo. Aliás, é cada vez mais constante o consumo de produtos do circuito inferior pela classe média da sociedade, o que comprova a tese de Santos (2007), segundo a qual todas as classes sociais podem consumir fora do circuito ao qual estão mais ligadas, mesmo que esse consumo seja apenas ocasional ou esporádico.

A expansão do circuito inferior em João Câmara também se dá por meio da comercialização de produtos típicos do circuito superior como é o caso dos aparelhos de celular, que, a cada dia, se fazem mais presentes no seio da sociedade. De acordo com Silveira (2004), se são as grandes corporações que dominam a produção e a venda desses objetos, o restante da circulação é realizada por outros agentes, sendo que são aqueles pertencentes ao circuito inferior que fazem com que esses produtos cheguem às mãos das camadas mais pobres da sociedade.

A difusão maciça do telefone celular entre aqueles grupos sociais que realizam atividades não-hegemônicas aparece como importante instrumento de trabalho, proporcionando que estes ampliem as suas fronteiras de trabalho e garantam, desse modo, a realização de mais negócios. Na realidade de João Câmara, a título de exemplificação, podemos destacar: moto-taxistas, pedreiros, marceneiros, mercadinhos, pequenas pizzarias, entre outras formas de trabalho e de comércio, que usam diariamente esse objeto técnico como forma de realização de seus negócios. É interessante lembrar que o telefone celular faz parte do rol de objetos técnicos que Milton Santos (2000) chamou de dóceis e flexíveis, justamente porque são passíveis de serem apropriados para finalidades diversas das quais foram concebidas.

É preciso destacar que a difusão maciça desse novo objeto técnico, o celular, próprio do período histórico atual, não só vem proporcionando a criação de pequenos estabelecimentos destinados à sua comercialização, mas também de estabelecimentos que são destinados ao conserto e manutenção dos aparelhos, bem como fomenta o aparecimento de um amplo mercado voltado para venda de acessórios, como: capas, baterias, bolsinhas, adesivos etc.; tais atividades são realizadas em sua maioria por ambulantes ou pequenos comerciantes que trazem essas formas de trabalho como a sua única fonte de renda.

Expressões das formas de consumo moderno que emergem nas metrópoles e representantes legítimas do circuito superior, as redes de eletrodomésticos e as de supermercados também fazem parte da configuração dos circuitos da economia urbana em João Câmara.

Tais redes se expandem, cada vez mais, pelo território porque praticam formas de organização que permitem compras em grandes volumes com melhores preços e condições na forma de pagamento das mercadorias. Tal situação possibilita que estabeleçam melhores preços para a revenda de seus produtos, o que, quando somado à grande flexibilidade em suas formas de pagamento, funciona como atrativo e estímulo ao consumo.

No caso das redes de eletrodomésticos, constatamos a existência de três, a Unilar, a Maré Mansa e as Casas França . Uma característica marcante dessas redes é que elas, em muitos casos, direcionam-se para atender as necessidades de consumo de um público tipicamente do circuito inferior e tentam atrá-los por meio de facilidade no crédito como uso de carnês ou crediários, com o financiamento da própria loja.

Tais redes atuam em várias parcelas do território Potiguar e em muitos casos concorrem de igual para igual com grandes redes nacionais, como, por exemplo, a Insinuante e a Rabelo. Em 
João Câmara, a consequência direta da expansão dessas redes, em muitos casos, é o fechamento de inúmeros outros pequenos estabelecimentos, que não dispondo dos mesmos mecanismos de compra de mercadorias acabam sucumbindo diante da forte concorrência.

Quanto às redes de supermercados que se fazem presentes em João Câmara, destacamos a Rede Mais, que se constitui num dos mais sólidos grupos de supermercados do Estado do RN. A lógica de funcionamento, bem como as consequências da inserção dessa rede na cidade são as mesmas daquelas das redes de eletrodomésticos. Entretanto, destacamos que ainda que várias pequenas bodegas não resistam à concorrência estabelecida por essa rede, constatamos que muitos ainda sobrevivem no mercado, graças ao desenvolvimento de relações que não se explicam pela racionalidade do capital. Exemplo concreto é a prática do fiado ou das "cadernetas", que na realidade consiste em um crédito informal estabelecido pela relação de proximidade e de confiança entre o cliente e proprietário do estabelecimento.

Há ainda uma variedade de estabelecimentos de comércio e de prestação de serviços como salões de cabeleireiro, bares, lanchonetes, pontos de mototáxi, loja de material de construção, de ferramentas, além de pequenas mercearias e mercadinhos. Todos esses estabelecimentos se localizam nos mesmos subespaços de maneira contigua, formando um espaço densamente ocupado que em dias intensos chegam a lembrar as grandes cidades

É preciso destacar que não constatamos a existência de áreas de especialização urbana em uma única atividade ou ramo, mas de áreas de diversificação, nas quais predominam múltiplos circuitos espaciais de produção conforme destaca Silveira (2004). Desse modo, fica evidenciado que nessa área da cidade o processo de trabalho apresenta diversas formas de realização, dado que se constitui num subespaço no qual coexistem técnicas de diversos períodos históricos

Outro ponto importante para compreensão do circuito inferior em João Câmara é a feira livre semanal. Correia (1981), já havia destacado o papel dessas para as cidades nordestinas, sobretudo porque elas formam um traço de união entre o campo e a cidade. Tais feiras livres apresentam grande dinâmica territorial, pois envolvem em um mesmo espaço produtores e comerciantes das mais variadas naturezas e de vários pontos do território, que convergem para a cidade a fim de comercializarem produtos diversos, tais como: hortifrutigranjeiros, carnes, peixes, frutas, cereais, legumes, ferramentas agrícolas, roupas, calçados etc. Em suma, uma diversidade de produtos que nos revelam um intenso movimento no território, bem como a existência de múltiplos circuitos espaciais de produção que se imbricam em um mesmo espaço para configurarem uma das maiores feiras livres do território potiguar.

Assim, a feira livre semanal de João Câmara representa o momento de maior dinâmica do comércio da cidade não somente para aqueles que possuem bancas na própria feira, mas também para todo comércio da cidade. De acordo com um comerciante local, a feira livre semanal representa de $30 \%$ a $40 \%$ de todo o seu faturamento mensal. Isto se deve ao fato de que a circulação na cidade é muito intensa, tanto a partir de fluxos populacionais advindos da área rural de João Câmara, quanto dos vários municípios que estão sob a influência da cidade.

Além da área central e da feira livre, outro subespaço que apresenta intensa dinâmica territorial na cidade são as margens da Rodovia BR 406, que tem em João Câmara um importante ponto de apoio para inúmeros caminhoneiros e comerciantes que circulam diariamente por essa Rodovia. Aliás, a BR 406 é um dos principais espaços de fluxos do território potiguar, dado fazer uma interação espacial da região metropolitana de Natal com a região de Macau, e a cidade de João Câmara, por estar localizada às margens desse subespaço, apresenta um número considerável de estabelecimentos que se relacionam com os fluxos que cortam essa rodovia federal.

Este trecho da cidade abriga uma significativa quantidade de pequenos restaurantes, lanchonetes, pousadas, oficinas e postos de combustíveis que atendem um público bastante diversificado. São um total de 7 postos de combustíveis de várias bandeiras nacionais e mundiais (Ale, Esso, Petrobras, por exemplo) e mais de 20 estabelecimentos entre pousadas e restaurantes, situados somente às margens da Rodovia BR 406. É preciso destacar que esse considerável número de postos de 
combustíveis e pousadas dá-se também pela situação geográfica de João Câmara na rede urbana da micro região de Baixa verde, uma vez que a maioria dos comerciantes responsáveis pelas revendas nos municípios da região tem na cidade um ponto de apoio permanente.

A cidade de João Câmara também apresenta alguns espaços mais voltados para a realização de funções mais modernas da cidade contemporânea, através da existência de atividades que se orientam de acordo com a atual divisão internacional hegemônica do trabalho (SILVEIRA, 2004). Desse modo, constatamos que o circuito superior também se faz presente na economia de João Câmara, por meio da presença de duas grandes concessionárias de motocicletas multinacionais: as empresas Honda e Yamaha. A existência dessas empresas mundiais na cidade de João Câmara, ocorre porque no período histórico atual os espaços estão cada vez mais abertos aos investimentos do exterior (ISNARD, 1978).

Lembramos também que a presença dessas empresas no município de João Câmara vem proporcionando uma intensa expansão de motocicletas, não somente na cidade em foco, que apresenta uma das maiores frotas de todo estado, mas também nos municípios que estão em seu entorno. De acordo com dados do IBGE, em 2010 o município de João Câmara tinha 2.733 motocicletas; tal número sofreu um incremento de aproximadamente 150 motocicletas, se considerarmos o ano de 2011. Tal expansão encontra nexo na difusão dos sistemas de créditos que facilitam sobremaneira o consumo desses objetos técnicos, especialmente para os aposentados e para aqueles que apresentam uma renda fixa e que tem, desse modo, a oportunidade de realizar diversas formas de financiamento.

Esses espaços organizados verticalmente, embora sejam portadores de uma racionalidade hegemônica, pari passu, com os interesses das grandes corporações, vem engendrando espaços que são organizados horizontalmente, pois atendem aos interesses dos agentes sociais locais, sobretudo, àqueles do circuito inferior da economia urbana. Assim, ao mesmo tempo em que temos em João Câmara o aumento de motocicletas, número este incrementado sobremaneira após a chegada das empresas Honda e Yamaha, constatamos o surgimento de inúmeras pequenas lojas de peças novas, usadas e de "genéricas", que surgem para atender a esta grande demanda existente na cidade.

\section{CONSIDERAÇÕES FINAIS}

Em síntese, a problemática ora exposta evidencia que os circuitos adquirem formas diversas de existência que emergem a partir da relação contraditória entre as condições socioespaciais de cada parcela do território e os eventos externos, que como diria Santos (2006), tanto tem o poder de transformar uma fração do espaço, dando-lhe um novo conteúdo, quanto sofre as interferências desse mesmo espaço que muitas vezes muda sua forma de existência.

A partir do que foi explicitado podemos compreender porque nos últimos anos a economia urbana de João Câmara vem sofrendo uma intensa expansão de suas atividades, principalmente àquelas do circuito inferior da economia, que entendemos que abarca mais de $90 \%$ do total de estabelecimentos da cidade, uma vez que apresentam baixo nível de incorporação tecnológica, de organização e de capital.

Desse modo, constata-se que a expansão das atividades econômicas em João Câmara está profundamente atrelada ao crescimento do circuito inferior da economia e com o aumento do consumo entre as camadas mais pobres da sociedade. Além disso, constatou-se que a expansão dos dois circuitos da economia, sobretudo o circuito inferior, tornou-se o lócus de reprodução de diversas formas de trabalho precário, bem como o abrigo para a reprodução da existência das camadas mais pobres da sociedade.

\section{REFERÊNCIA BIBLIOGRÁFICA}

BRASIL, Instituto Brasileiro de Geografia e Estatística. Cidades: Rio de Janeiro, 2010. 
BRASIL, Instituto Brasileiro de Geografia e Estatística. Censo Demográfico: Estado do Rio Grande do Norte. Rio de Janeiro, 1970.

BRASIL, Instituto Brasileiro de Geografia e Estatística. Censo Demográfico: Estado do Rio Grande do Norte. Rio de Janeiro, 1980.

BRASIL, Instituto Brasileiro de Geografia e Estatística. Censo Demográfico: Estado do Rio Grande do Norte. Rio de Janeiro, 1991.

BRASIL, Instituto Brasileiro de Geografia e Estatística. Censo Demográfico: Estado do Rio Grande do Norte. Rio de Janeiro, 2000.

BRASIL, Instituto Brasileiro de Geografia e Estatística. Censo Demográfico: Estado do Rio Grande do Norte. Rio de Janeiro, $2010 \mathrm{~b}$.

BRASIL, Ministério do Desenvolvimento Social e Combate a Fome. Bolsa Família. Brasília (BRASIL, $2010 \mathrm{~d})$.

BRASIL, Ministério do Trabalho e Emprego. Cadastro Geral de Empregados e Desempregados (CAGED), Brasília. 2010c.

DIEESE. Departamento intersindical de estatísticas e estudos socioeconômicos. Estudos e pesquisas. São Paulo, 2007.

CDL - Câmara dos dirigentes lojistas de João Câmara. Estatísticas. João Câmara, 2010.

CLEMENTINO, Maria do Livramento Miranda. Economia e Urbanização: o Rio Grande do Norte na década de 70. Natal: UFRN. Ed. Universitária. 1997.

CONTEL, Fábio Betiole. Território e finanças: técnicas, normas e topologias bancárias no Brasil. 2006. 343 f. Tese Doutorado (Doutorado em Geografia Humana) - Universidade de São Paulo, São Paulo, 2006.

FELIPE, José Lacerda A. Elementos de Geografia do RN. Editora Universitária, Natal, 1986.

FELIPE, José Lacerda A. Rio Grande do Norte: Uma leitura geográfica. Natal, EDUFRN, 2010.

LIMA, Robeilza de O. Publicidade, consumismo e dívida na Região do Mato Grande - RN. Natal, 2006.

OASHI, Maria da Conceição Guimarães. Estudo da cadeia produtiva como subsídio para pesquisa e desenvolvimento do agronegócio do sisal na Paraíba. Tese de doutorado. Pós-Graduação em Engenharia de Produção da Universidade Federal de Santa Catarina, 1999.

OLIVEIRA, Francisco de. Elegia para uma Re(li)gião: SUDENE, Nordeste, Planejamento e conflito de classes. $3^{\mathrm{a}}$ ed. Rio de Janeiro: Paz e Terra, 1981.

SANTOS, Paulo Pereira dos Santos. Evolução Econômica do RN: Do século XVI ao século XX. Natal, Editora Clima, 1999.

SANTOS, Milton. O espaço dividido: os dois circuitos da economia urbana nos países subdesenvolvidos. São Paulo: Livraria Francisco Alves Editora S.A, 1979.

SANTOS, Milton. Manual de Geografia urbana. São Paulo: EDUSP, 1980.

SANTOS, Milton. Técnica, espaço e tempo: globalização e meio técnico-científico-informacional. São Paulo: Editora da Universidade de São Paulo, 1994.

SANTOS, Milton. A urbanização brasileira. 5. ed. São Paulo: Editora da Universidade de São Paulo, 2005.

SANTOS, Milton. A Natureza do espaço: técnica e tempo, razão e emoção. 4. ed. São Paulo: Editora da Universidade de São Paulo, 2006.

SANTOS, Milton. O espaço dividido: os dois circuitos da economia urbana nos países subdesenvolvidos São Paulo: Editora da Universidade de São Paulo, 2008.

SILVA, Rômulo Jarson Souza e. Perfil sócio-demográfico do município de João Câmara 1949-2000. Monografia de conclusão de especialização. UFRN, Natal, 2006.

SILVEIRA, Maria Laura da. Um país, uma região: fim de século e modernidades na Argentina. São Paulo: FAPESP, 1999.

SILVEIRA, Maria Laura da. Globalización y Circuitos de la Economía Urbana en Ciudades Brasileñas. Cuadernos del Cendes. A. 21. N. 57, tercera época, septiembre-diciembre 2004, p. 1-21. 
SILVEIRA, Maria Laura da. Crises e Paradoxos da Cidade Contemporânea: os Circuitos da Economia Urbana. In: Anais do X SIMPURB, Florianópolis, 2007 a.

SILVEIRA, Maria Laura da. Metrópolis brasileñas: un análisis de los circuitos de la economía urbana. Revista Eure. Santiago de Chile, vol. XXXIII, n. 100, diciembre de 2007. 2007b, p. 149-164.

SOUZA, Maria Adélia de. A metrópole e o futuro: a dinâmica dos lugares e o período popular da História. In: SOUZA, Maria Adélia de. (Org.). A metrópole e o futuro: refletindo sobre Campinas. Campinas: Edições Territorial, 2008, p. 35-53.

TAKEIA, Denise Monteiro. Um outro Nordeste: O algodão na economia do Rio Grande do Norte (19001915). In: Projeto História. São Paulo, PUC, 1981.

TORQUATO, Aldo et al. Baixa Verde: Raízes de Nossa História. João Câmara, 2009.

Trabalho enviado em maio de 2012 Trabalho aceito em junho de 2012 